\title{
Re-Positioning Assessment for Children's Creativity and Teachers' Creativity Fostering Behaviours: A Case Study of Kindergarten Curriculum Reform Efforts
}

\author{
Christina Chi Weng Sung, Keang Ieng Peggy Vong \\ Faculty of Education, University of Macau, Macau SAR, China \\ Email: christina.cwsung@gmail.com
}

How to cite this paper: Sung, C. C. W., \& Vong, K. I. P. (2021). Re-Positioning Assessment for Children's Creativity and Teachers' Creativity Fostering Behaviours: A Case Study of Kindergarten Curriculum Reform Efforts. Creative Education, 12, 1419-1437. https://doi.org/10.4236/ce.2021.127108

Received: May 24, 2021

Accepted: June 29, 2021

Published: July 2, 2021

Copyright () 2021 by author(s) and Scientific Research Publishing Inc. This work is licensed under the Creative Commons Attribution International License (CC BY 4.0).

http://creativecommons.org/licenses/by/4.0/

\begin{abstract}
This study explored the role of assessment to effectively facilitate curriculum reform aiming to foster children's creativity and teachers' creativity fostering behaviours (CFB). A "flipped-measure" was introduced by deliberately positioning a mode of formative assessment in the centre of the curriculum modifications, rather than after modifications. Children's creativity was measured using the Preschoolers' Creativity Test and teachers' CFB was measured with the Creativity Fostering Teacher Behaviour Index (CFTIndex) at three-time intervals during one academic year. Results showed that the newly-adopted child-centred curriculum and pedagogy, which was launched concurrently with a formative assessment, significantly enhanced children's creativity ( $p$ $<.001)$ and teachers' CFB $(p=.001)$. The findings suggested that the mode of an assessment scheme, "re-positioning" of formative assessment and curriculum modifications, all play important roles in leading a curriculum reform geared towards promoting children's creativity and teachers' CFB.
\end{abstract}

\section{Keywords}

Assessment in Kindergartens, Child-Centred Curriculum, Creativity, Creativity Fostering Behaviours, Curriculum Reform

\section{Introduction}

In this era of globalisation and rapid technological innovations, educators are calling for a paradigm shift in education that would help future generations to become adaptable in this fast-changing and competitive world (Seng, 2000). However, school administrators and teachers are challenged to develop curricula 
that would cultivate children's generic skills to cope with this constant changing environment (Yan, 2015). The current educational culture worldwide still focuses on conformity and standardised testing, which contradicts with the principles that helps to facilitate students' generic skills (Robinson, 2013). The "teach to the tests" approach (Berry, 2011) is manifested when the school administrators aim to enhance the schools' reputation by increasing students' achievement (Harris et al., 2013). Teachers then take a teacher-directed approach to make sure that students learn as much exam-related knowledge as possible, believing that would help them excel in examinations and be better prepared for future education or career. Under this approach, the counter-effects for young learners might turn them into passive and rote learners, and eventually lose the motivation to learn (Kirkpatrick \& Zang, 2011). Due to this educational malpractice, researchers and educators internationally still endeavour to launch effective reform in curriculum and assessment.

In the Chinese educational and cultural context, the importance of examination could be traced back to the Sui Dynasty in A.D. 603, where people with higher familiarity with the Confucian literature in the imperial examinations would have higher bureaucracy positions ( $\mathrm{Wu}, 2016)$. However, examination is still the predominant means to measure students' academic success in Chinese societies nowadays, such as the National College Entrance Examination in mainland China, the Hong Kong Diploma of Secondary Education Examination (HKDSE) in Hong Kong SAR (Special Administrative Region) of China, and the Joint Admission Examination of Four Higher Education Institutions (JAE) in Macao SAR of China. Examination scores are used to distinguish the academically "successful" students from "unsuccessful" ones and direct them towards different academic tracks and future careers respectively, which could in general shape their social status in the future (Yan, 2015). This highly exam-oriented education culture has caused teachers to shoulder great pressure and devote most of their time in covering all the teaching materials in an academic-focused curriculum within a scholastic year (Chan \& Yuen, 2014). Consequently, teachers focus on transmitting knowledge to students rather than fostering their generic skills, and tend to be more reluctant to innovate (Chan \& Yuen, 2014; Li \& Li, 2019).

In recent years, an increasing number of kindergartens in the Chinese context have started to implement curriculum reform geared towards a child-centred environment (Berry, 2011; Yu et al., 2006), and most of them took a "common approach" to curriculum reform, i.e. their reform efforts focused primarily on modifying the curriculum in terms of its contents and pedagogy, but made no changes to the "paper-and-pencil" assessment mode that is deeply-rooted in the Chinese educational culture. Unfortunately, implementing curriculum reform with this "common approach" has always been far from successful (Yan, 2015). Many educators have neglected that the mode of assessment would have an impact on the overall teaching and learning environment, which might lead to an 
ineffective curriculum reform. In the current study, a local private kindergarten in Macao initially took a "common approach" to curriculum reform geared towards a child-centred and creative environment. This initial curriculum reform had been far from successful, in which the reform's initial efforts yielded minimal creativeness of classroom activities and teaching strategies. The current study challenged the "common approach" to curriculum reform. It explored whether modifying the mode of assessment (from summative to formative), and more importantly, placing a central role to its "new" assessment scheme, would lead to effective modifications in its curriculum and pedagogy, i.e. bringing benefits to children's creativity and teachers' creativity fostering behaviours (CFB). The current study furnishes a response to the dearth of research on the role of assessment in curriculum reform, and hopefully with its empirical evidence highlighting the crucial manipulations of the mode of assessment within a curriculum reform process, provides theoretical and practical implications for educators and policy makers.

\section{Literature Review}

Fullan (2001) proposed three phases, including initiation, implementation and continuation, that would affect the final outcome of the implementation of the reform process. Initiation refers to the process of originating a decision to proceed with an educational change. Some factors affecting initiation include advocacy from school administrators and teachers, and government new policy. Implementation refers to the process of putting new ideas into practice. Factors affecting implementation include characteristics of the reform, for example, the need for change, complexity and practicality of the new program; local factors such as school administrators and teachers; and external factors such as government. Continuation refers to the extension of the implementation phase. It refers to whether the change is provided with continuous modifications or becomes unnoticeable due to discarding or conflict of ideas. Lastly, the outcomes depend on whether the objectives are achieved, and whether students' learning and development are enhanced (Fullan, 2001). This theory of educational change not only provides a deeper understanding of the phases within a reform process, but also the importance of transforming multiple components to reach a lasting and complete implementation of curriculum change.

\subsection{From Summative to Formative Assessments in Early Years}

Dunphy (2010) stated that "assessment in early childhood is about making the range of children's learning visible" (p. 52). The traditional form of summative assessment, usually in the form of "paper and pencil" test and examinations, could not provide children with opportunities to exhibit their full range of competence due to the restricted setting (Berry, 2008; Pellegrini, 2001). Moreover, children's development trajectory and learning progress is complex, which means assessing children's achievements could be difficult or superficial through 
summative assessment in the early years (Aras, 2019). Whereas, formative assessment, such as learning portfolios, allows teachers to obtain more meaningful information about children's learning and development through their daily activities which promotes continuous teaching and learning modifications (Aras, 2019; Berry, 2008; Brown, 2005; Dunphy, 2010; Pyle \& DeLuca, 2017; Wiliam, 2011).

In the Chinese contexts, there is a long tradition of attaching great importance to education since helping students attain high academic achievement would mean bolstering their upward social mobility (Zhao, 2018). Nonetheless, in recent years, there is a trend of reform in seeking to move away from the high-stakes summative examinations towards a formative assessment to promote more active learning amongst students, especially in the early years (Berry, 2011; Yu et al., 2006). More attention is being placed on students' learning process and progress rather than the ranking of students' achievement. However, challenges are encountered when establishing formative assessment within a kindergarten in a highly exam-oriented education culture in Chinese societies.

A summative assessment that mainly distinguishes the ranking of students' achievement has a negative backwash effect on the overall teaching and learning environment (Alderson \& Wall, 1993; Cheng, 1997; Curtis \& Cheng, 2004), which leads to a teacher-directed curriculum and pedagogy and decreases children's motivation to learn (Kirkpatrick \& Zang, 2011). Previous research showed that the National College Entrance Examination and HKDSE has a domino negative effect on the assessment and curriculum in secondary education, which further influences primary and early childhood education (Berry, 2011; Yan, 2015). It has become clear that the mode of assessment would have an impact on the overall teaching and learning environment. Although formative assessment has been recognised as important in existing literature in terms of boosting students' interests in learning and academic performance (Berry, 2008), educators are still grappling with ways to adapt to formative assessment, either its contents or implementation.

Teachers' reform efforts always focus primarily on modifying the curriculum in terms of its contents and pedagogy rather than other important components, such as the mode of assessment, subsequently led to ineffective curriculum reforms (Yan, 2015). The "new approach" adopted in the current study might provide a deeper understanding of the role of assessment in curriculum reform and reveal the key factors in adopting a new mode of assessment, if it were to bring real changes in children and teachers. It thereby proposed the following research questions: 1) Are there any significant improvements in children's creativity due to the newly-adopted child-centred curriculum modifications and formative assessment? 2) Are there any significant improvements in teachers' CFB due to the effect of the newly-adopted child-centred curriculum modifications and formative assessment? 3) Do teachers' CFB lead to any changes in children's creativity? 


\subsection{Macao Schools}

Macao was colonised by the Portuguese in the $16^{\text {th }}$ century. With much cultural influence from Southern Europe for over 400 years, Macao has acquired certain Southern European values and characteristics which distinguish it from other Chinese cities. Unsurprisingly, there are differences between Macao's education system in the colonial and post-colonial period. During the colonial period, the Portuguese Government took a "laissez-faire" educational policy in which the education of Chinese-speaking children was left to the European missionaries, local vocational groups, and local community (Lo, 2005; Wong \& Rao, 2004). After the Macao Government was established in 1999 following the handover of Macao to the Chinese government, it has taken a more active role in enhancing the quality of early childhood education by setting up various guidelines. In 2014 and 2015, the Formal Curriculum Framework for Local Schools and the Requirements of Basic Academic Competencies in Early Childhood Education were released (Macao Special Administrative Region, 2014; 2015). Children's holistic development through exploration and learning through play, and generic skills, such as creativity, social and communicative skills, that could help children become lifelong learners were emphasised in these documents. Subsequently, an increasing number of kindergartens had started to conduct curriculum reform in terms of their contents and pedagogy. Most kindergartens have been implementing a thematic-based approach, combining with other approaches, such as High Scope and corner play (Vong \& Vong, 2017). However, these attempts in Macao are yet to be proven effective in developing children's creativity. Some studies have shown that developing and implementing curriculum reform of similar natures have been far from successful (Wu, 2016; Yan, 2015). The futile attempts seem to be linked to the "backwash effect", i.e. the misalignment between the call for a child-centred curriculum and the highly summative assessment ( $\mathrm{Wu}, 2016$; Yan, 2015). Given the historical role of assessment in the Chinese educational system, assessment should be considered as a crucial and indispensable part of the changes introduced within the reform process (Posner, 1994).

\section{The Present Study}

The present study followed a one-year reform process at a local private kindergarten in Macao and used this as a case study for a more in-depth understanding of the role of assessment in curriculum reform. This research context is a typical kindergarten, in which it is of medium size in terms of the number of children and the kindergarten scale in Macao. Moreover, the location of the kindergarten is neither in the city centre nor too remote from the residential areas. Students in this kindergarten came from different social and economic backgrounds which could represent the whole population. The reform process was differentiated into (1) the "old curriculum" before the present study; and the "newly-adopted curriculum", which was further divided into (2) and (3), i.e. first and second phases (see Appendix A). 


\subsection{The "Old Curriculum"}

The reform rationale was that the teachers, stimulated by new government guidelines and progressive ideas from professional development training, found the "teach to the tests" approach and a heavily academic-oriented curriculum unsuitable for children's learning and development, and sought to fostering children's core abilities as their children's learning goals: creativity, communication, collaboration and problem solving. The kindergarten had taken an initial attempt to modify its curriculum by adding certain child-centred elements into the curriculum, in which a thematic approach consisting of a whole-group thematic session followed by small-group activities in learning corners and a whole-group sharing session was embraced. Yet, there was a mismatch amongst the mode of teachers' pedagogy, the assessment and the curriculum. A teacher-directed pedagogical mode, pre-designed teaching aids and activities, and a "paper-and-pencil" assessment scheme were still adopted. Thus, the changes made to the curriculum and the benefits that the child-centred curriculum that were supposed to create could not be reflected much on children.

\subsection{The "Newly-Adopted Curriculum"—First Phase}

The kindergarten then decided to distant itself from the conventional thematic approach, and continued to modify its curriculum, but by first introducing drastic changes to the mode of assessment. The summative "paper-and-pencil" assessment scheme was eliminated and the "Child Development and Learning Portfolio" was introduced as a new mode of formative assessment. Children's learning progress were documented and evaluated through daily observations, photos, video recordings, and children's artwork. The kindergarten continued to embrace the child-centred curriculum, but more time, space and autonomy were allowed. Although changes were being made to the mode of assessment, it carried a strong focus on designing activities for children. In this transition period, teachers' pedagogies were still teacher-directed, and activities and teaching materials were still pre-designed and close-ended in this transition period.

Teachers tried to collect information to include in the Learning Portfolio. However, the first phase was too modest which caused teachers to find difficulties in fulfilling the contents in the Learning Portfolio. Teachers could not get children to express ideas relating to the topics, and hence, could not obtain much information to support the development of the four core abilities involved in the Learning Portfolio. At this stage, there was still a mismatch between the mode of assessment and the curriculum due to the fact that their curriculum and pedagogy were still fundamentally teacher-directed, but their formative assessment was put into place. This led to the second phase of the "newly-adopted curriculum".

\subsection{The "Newly-Adopted Curriculum" - Second Phase}

The kindergarten had shifted away from a teacher-directed to a more child-centred 
pedagogical mode. Teachers discussed a theme with children using open-ended questions, so as to set up the contents of the activities in accordance with children's interests, experiences and capabilities. Learning corners were eliminated, and classrooms were opened up to create more space and autonomy for children to think and create. During the open classroom activities, teachers provided guidance and used open-ended questions to scaffold children's ideas. Open-ended materials were provided for children, and the amount of time given to children for the open classroom activities depended on their progress which created a much more flexible schedule in the curriculum. After the activities, children shared with their peers and teachers of the process, outcome, obstacles, and improvement plans of their open classroom activities. At this stage, teachers were able to collect information and record children's learning progress and core abilities fulfilling the Learning Portfolio, with a strong focus on capturing children's emotions and expression of ideas, making the formative assessment in practice and goal in alignment with the curriculum and teachers' pedagogical mode.

\section{Research Design}

\subsection{Participants}

A total of 187 children participated in the current study, involving 88 four-year-old children (mean age in months: 50.29; age range in months: 46 - 61; 54 boys and 34 girls) from four K2 classes, and 99 five-year-old children (mean age in months: 63.33; age range in months: 58 - 71; 52 boys and 47 girls) from four K3 classes. Parents' consent was obtained through the head teachers of each class. Eight head teachers and seven teacher assistants teaching these children participated in the current study.

\subsection{Measures}

The Preschoolers' Creativity Test (Yeh et al., 2006) was adopted to assess children's creativity. It consists of two subtests-Number Association and Situation-based Problem Solving. The Number Association subtest evaluates novelty. Two numbers (two sections: 7 and 9) were given and participants had to draw objects that are relevant to the shapes of the numbers. The answering time for each section in this subtest is 10 minutes. The Situation-based Problem-solving subtest evaluates usefulness. Two stories (two sections: reduce heat; retrieve kite stuck in a tree) were told where the story main character encountered some problems and participants were asked to help solve the problems. A total of 30 objects were provided to children and they had to select the objects that are useful to help solve the problems. The answering time for each section in this subtest is five minutes. The Preschoolers' Creativity Test showed acceptable test-retest reliability of .69 , and good inter-rater reliability of .97 for novelty and .99 for usefulness. This test also showed good criterion-related validity (Yeh et al., 2006).

The Creativity Fostering Teacher Behaviour Index (CFTIndex) (Soh, 2000) is 
a widely-used assessment used to assess teachers' CFB during their interaction with students. CFTIndex was developed based on the nine General principles suggested by Cropley (1997) for teachers to foster creativity in students: independence, integration, motivation, judgement, flexibility, evaluation, questions, opportunities, and frustration. Teachers self-rated their CFB on the CFTIndex questionnaire which involved 45 items presented with an 11-point Likert scale, with 0 for never and 10 for all the time. The CFTIndex showed good internal consistency reliability of .96 and concurrent validity (Soh, 2015).

\subsection{Procedures}

The study employed a design with pre-test, mid-test and post-test, and with an intervention in between each test. The pre-test was held at the beginning of the scholastic year and was served as baseline data. Children's creativity was assessed using the Preschoolers' Creativity Test. Those who were absent on the day of assessment completed the test once they returned to school. Teachers' CFB was assessed using the self-rated CFTIndex questionnaire. After the pre-test, came the first phase of the newly-adopted curriculum which lasted for 13 weeks. The mid-test was conducted towards the end of the first school term when the implementation of the newly-adopted child-centred curriculum and formative assessment was getting more stable. Children's creativity and teachers' CFB were assessed for the second time. After the mid-test, came the second phase of the newly-adopted curriculum which lasted for 15 weeks. The post-test was held by the end of the scholastic year when the implementation of the newly-adopted child-centred curriculum and formative assessment was in full force. Children's creativity and teachers' CFB were assessed for the third time.

\subsection{Statistical Analysis}

Analyses of the quantitative data were performed using IBM SPSS Statistics version 23. Firstly, regression analysis was conducted to account for the effect of age on children's creativity scores. Paired samples t-test and repeated measures ANOVA were conducted to examine the effect of the newly-adopted child-centred curriculum and formative assessment on children's creativity and on teachers' CFB. Lastly, regression analysis was conducted to examine whether teachers' CFB predicts children's creativity.

\section{Findings}

\subsection{The Effect of Child-Centred Curriculum and Formative Assessment on Children's Creativity}

The descriptive statistics of the pre-test, mid-test and post-test of children's creativity scores are presented in Table 1 . Higher scores indicate higher creativity. There was an increase in four-year-old and five-year-old children's creativity overtime, and five-year-old children had higher creativity than four-year-old. 
Table 1. Means and standard deviations of pre-test, mid-test and post-test creativity scores.

\begin{tabular}{cccccccccc}
\hline & \multicolumn{3}{c}{ Pre-test } & \multicolumn{3}{c}{ Mid-test } & \multicolumn{3}{c}{ Post-test } \\
\cline { 2 - 10 } & $M$ & $S D$ & $N$ & $M$ & $S D$ & $N$ & $M$ & $S D$ & $N$ \\
\hline Four-year-old children & 46.7 & 7.55 & 88 & 54.2 & 10.2 & 88 & 60.2 & 12.4 & 88 \\
Five-year-old children & 52.2 & 12.4 & 99 & 57.6 & 11.0 & 99 & 67.9 & 16.1 & 99 \\
Total & 49.6 & 10.7 & 187 & 56.0 & 10.7 & 187 & 64.3 & 15.0 & 187 \\
\hline
\end{tabular}

Assuming that there were no effects of the child-centred curriculum and formative assessment on children's creativity, the creativity scores of four-year-old children in mid-test and post-test should be similar to those of five-year-old children in pre-test and mid-test. Interestingly, the creativity scores of four-year-old children in mid-test $(M=54.2, S D=10.2)$ and in post-test $(M=$ $60.2, S D=12.4)$ were greater than those of five-year-old in pre-test $(M=52.2$, $S D=12.4)$ and in mid-test $(M=57.6, S D=11.0)$. This suggested that there might be effects of the child-centred curriculum and formative assessment on children's creativity.

The assumptions of multicollinearity, homoscedasticity and normal distribution of the data were examined and whether these assumptions have been violated were reported. Normal Predicted Probability (P-P) plot and Cook's D were examined to determine the normal distribution of the data. The P-P plot for the models illustrated a linear distribution which thereby indicated normal distribution. The Cook's Distance values were all under 1, suggesting individual cases were not unduly influencing the models, further verifying a lack of outliers. The next assumption check is homoscedasticity. Examining the data using a scatterplot between the standardised residuals and the standardised predicted values showed that the data points were equally distributed and scattered randomly, indicating homoscedasticity. The last assumption check is multicollinearity. Analyses of collinearity statistics showed that this assumption had been met, as VIF scores were all under 1 (VIF scores between 1.0 - 1.096).

In order to claim that the improvements in children's creativity is predominantly due to the effect of the newly-adopted child-centred curriculum and formative assessment, regression analysis was conducted to account for the effect of age in mid-test and post-test early on in the analysis process. Firstly, a regression analysis was conducted to account for the effect of age in mid-test: 1) effect of age, 2) effect of pre-test creativity, and 3) effect of age and pre-test creativity on mid-test creativity were tested respectively. When compared the $\mathrm{r}^{2}$ among the three regression models, $3 \%$ of variability in mid-test creativity was explained by age, $20 \%$ of variability in mid-test creativity was explained by pre-test creativity and $20.2 \%$ of variability in mid-test creativity was explained by age and pre-test creativity. From this, it was indicated that the effect of age towards mid-test creativity was not as strong as the effect of pre-test creativity towards mid-test creativity. 
Secondly, a regression analysis was conducted to account for the effect of age in post-test: 1) effect of age, 2) effect of pre-test creativity, and 3) effect of age and pre-test creativity on post-test creativity were tested respectively. When compared the $\mathrm{r}^{2}$ among the three regression models, 9\% of variability in post-test creativity was explained by age, $12.7 \%$ of variability in post-test creativity was explained by pre-test creativity and $16.8 \%$ of variability in post-test creativity was explained by age and pre-test creativity. From this, it was indicated that the effect of age towards post-test creativity was not as strong as the effect of pre-test creativity towards post-test creativity.

Thirdly, a regression analysis was conducted to account for the effect of age in post-test: 1) effect of age, 2) effect of mid-test creativity, and 3) effect of age and mid-test creativity on post-test creativity were tested respectively. When compared the $\mathrm{r}^{2}$ among the three regression models, 9\% of variability in post-test creativity was explained by age, $17.3 \%$ of variability in post-test creativity was explained by mid-test creativity and $22.5 \%$ of variability in post-test creativity was explained by age and mid-test creativity. From this, it was indicated that the effect of age towards post-test creativity was not as strong as the effect of mid-test creativity towards post-test creativity.

Paired-samples t-test was carried out to examine the differences among pre-test, mid-test and post-test creativity scores. Results showed that children in mid-test $(M=56.0, S E=.790)$ had significantly higher creativity scores than those in pre-test $(M=49.6, S E=.780), t(186)=-7.72, p<.001$. Children in post-test $(M=64.3, S E=1.10)$ had significantly higher creativity scores than those in pre-test $(M=49.6, S E=.780), t(186)=-13.37, p<.001$. Children in post-test $(M=64.3, S E=1.10)$ had significantly higher creativity scores than those in mid-test $(M=56.0, S E=.790), t(186)=-7.89, p<.001$.

Repeated measures ANOVA was conducted to examine the effect of the newly-adopted child-centred curriculum and formative assessment on children's creativity in mid-test and post-test. Mauchly's test indicated that the assumption of sphericity was violated, $\chi^{2}(2)=20.10, p<.001$. Thus, the $\mathrm{df}$ were corrected using Huynh-Feldt Correction estimates of sphericity $(\varepsilon=.92)$. The univariate results showed an effect of the child-centred curriculum and formative assessment on creativity scores, $F(1.83,340)=108.56, p<.001$. Figure 1 shows the plot of creativity scores overtime.

\subsection{The Effect of Child-Centred Curriculum and Formative Assessment on Teachers' CFB}

The mean scores of the nine subscales and combined score of CFTIndex of 15 teacher participants for the pre-test, mid-test and post-test are presented in $\mathrm{Ta}$ ble 2. Higher scores indicate higher CFB. Teachers in post-test had a higher mean score in each subscale than those in pre-test and mid-test. Teachers in mid-test had a higher mean score in each subscale than those in pre-test. Overall, teachers in post-test had a higher combined mean score of the CFTIndex than those in pre-test and mid-test. 


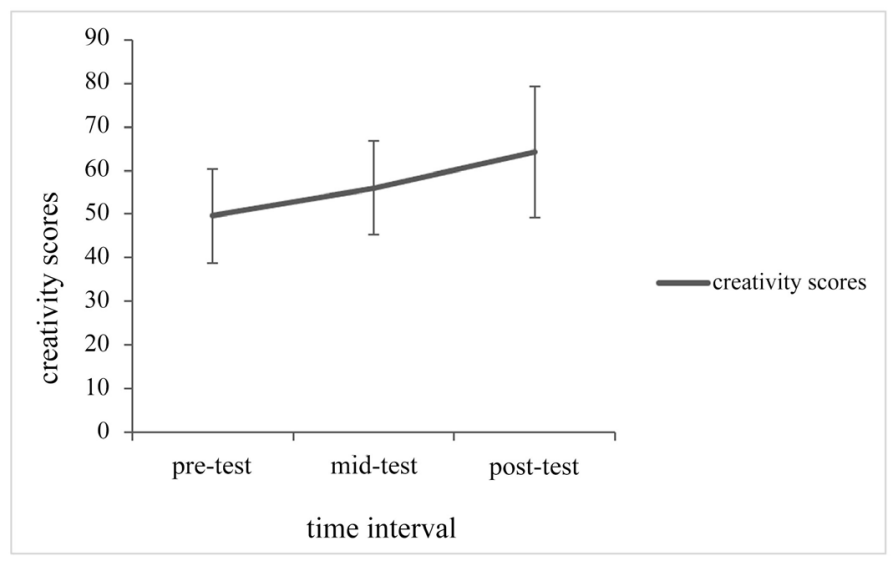

Figure 1. Plot of creativity scores in pre-test, mid-test and post-test.

Table 2. Means and standard deviations of pre-test, mid-test and post-test CFTIndex.

\begin{tabular}{ccccccc}
\hline & \multicolumn{2}{c}{ Pre-test } & \multicolumn{2}{c}{ Mid-test } & \multicolumn{2}{c}{ Post-test } \\
\cline { 2 - 7 } & $M$ & $S D$ & $M$ & $S D$ & $M$ & $S D$ \\
\hline Independence & 6.69 & 1.30 & 7.32 & .930 & 8.52 & .780 \\
Integration & 7.43 & 1.13 & 7.80 & .910 & 8.69 & .770 \\
Motivation & 6.97 & .840 & 7.48 & .770 & 7.87 & .800 \\
Judgement & 6.80 & 1.15 & 7.36 & .940 & 8.13 & .720 \\
Flexibility & 6.99 & .800 & 7.44 & .780 & 8.44 & .620 \\
Evaluation & 6.88 & .810 & 7.12 & .750 & 8.04 & .760 \\
Question & 7.24 & .770 & 7.44 & .770 & 8.13 & .770 \\
Opportunities & 7.55 & .760 & 7.72 & .780 & 8.32 & .780 \\
Frustration & 7.77 & .920 & 7.95 & .650 & 8.44 & .800 \\
CFTIndex & 7.15 & .780 & 7.51 & .700 & 8.29 & .670 \\
\hline
\end{tabular}

Paired-samples t-test analysis was carried out to examine the differences among the pre-test, mid-test and post-test CFTIndex. Teachers in post-test $(M=$ $8.29, S E=.170)$ had significantly higher CFTIndex than those in pre-test $(M=$ 7.15, $S E=.200), t(14)=-4.36, p=.001$. Teachers in post-test $(M=8.29, S E$ $=.170)$ had significantly higher CFTIndex than those in mid-test $(M=7.51, S E$ $=.180), t(14)=-7.00, p<.001$. Results showed no difference between pre-test and mid-test CFTIndex.

Repeated measures ANOVA was conducted to examine the effect of the newly-adopted child-centred curriculum and formative assessment on teachers' CFTIndex in mid-test and post-test. Mauchly's test indicated that the assumption of sphericity was violated, $\chi^{2}(2)=10.73, p=.005$. Thus, the df were corrected using the Greenhouse-Geisser Correction estimates of sphericity $(\varepsilon=.64)$. The univariate results showed an effect of the child-centred curriculum and formative assessment on teachers' CFTIndex, $F(1.28,17.9)=14.94, p=.001$. Figure 2 shows the plot of CFTIndex scores overtime. 


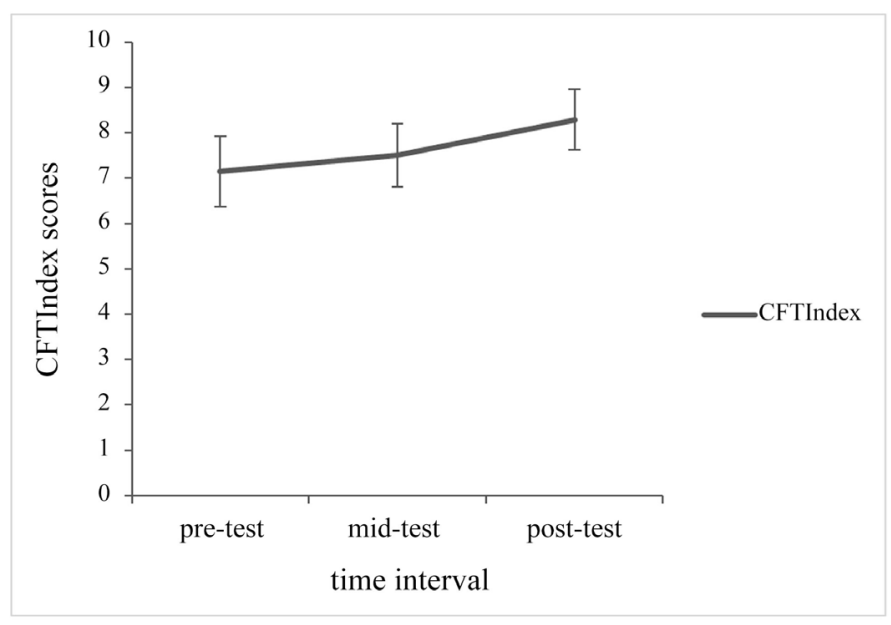

Figure 2. Plot of CFTIndex scores in pre-test, mid-test and post-test.

\subsection{The Effect of Teachers' CFB on Children's Creativity}

Regression analysis was conducted to examine whether teachers' CFB predicted children's creativity. The pre-test scores of teachers' CFTIndex significantly predicted the pre-test scores of children's creativity, $b=-4.76, S E=1.22, \beta=-.28, t$ $=-3.92, p<.001$. The mid-test scores of teachers' CFTIndex did not significantly predict the mid-test scores of children's creativity, $b=-.18, S E=1.05, \beta=$ $-.01, t=-.172, p=.863$. The post-test scores of teachers' CFTIndex did not significantly predict the post-test scores of children's creativity, $b=-.84, S E=1.58$, $\beta=-.04, t=-.531, p=.596$. Yet, when comparing the unstandardised coefficients and standardised coefficients of mid-test and post-test with pre-test, the values of both unstandardised and standardised coefficients of mid-test ( $b=$ $-.181, \beta=-.013)$ and post-test $(b=-.839, \beta=-.039)$ were smaller than those of pre-test $(b=-4.759, \beta=-.277)$. From this, it implied that teachers' CFB in mid-test and post-test had improved and this increase in teachers' CFB would lead to an increase in children's creativity.

\section{Discussion and Implications}

\subsection{The Effect of Child-Centred Curriculum and Formative Assessment on Children's Creativity}

From the point where the child-centred curriculum and formative assessment had been newly-adopted till where these were implemented in full force, children's creativity had gradually increased throughout the scholastic year. This result was consistent with existing research conducted by Vong and colleagues (2017), where children's creativity was increased after play opportunities were added to the curriculum.

The first phase of the newly-adopted curriculum in the reform process carried a strong focus on designing activities for children, but provided more room for children to direct their own learning, allowing them to plan what activities they wanted to engage in, what materials they wanted to use and with whom they 
wanted to collaborate with. The second phase, however, involved much more openness in the curriculum, including opening up the classroom, using open-ended materials and adopting scaffolding techniques to stimulate children's ideas. The contents of the thematic sessions and activities were developed based on children's learning progress, interests, experiences and capabilities. These modifications in the curriculum allowed children to think and create actively (Curtis \& Cheng, 2004), which was conducive to children's creativity. In addition, the formative assessment was in alignment with the child-centred curriculum which eliminated any drawbacks or negative backwash effect of assessment on the curriculum.

\subsection{The Effect of Child-Centred Curriculum and Formative Assessment on Teachers' CFB}

As seen from the results, the second phase of the newly-adopted curriculum and formative assessment in the reform process was strong enough to improve teachers' CFB significantly from mid-test to post-test. The Learning Portfolio allowed teachers to focus on capturing children's expression of ideas. Thus, teachers would adopt scaffolding techniques to stimulate and support children's ideas in order to fulfill the contents of the Learning Portfolio. The scaffolding techniques adopted in the second phase supported teachers' questioning and interactions between teachers and children, which prompted them to display more flexible strategies and more CFB.

Inversely, despite some modifications, the curriculum and pedagogical modifications in the first phase did not have a significant effect on teachers' CFTIndex from pre-test to mid-test. The reason for this could be due to the fact that from the "old curriculum" till the first phase of the newly-adopted curriculum, teachers mainly focused on designing activities for children, but not on teachers' pedagogical approach to enhance teachers' CFB. As a result, the modifications in the first phase had not significantly enhanced teachers' CFTIndex.

\subsection{The Effect of Teachers' CFB on Children's Creativity}

The scores of teachers' CFTIndex and children's creativity had increased overtime. Teachers' CFTIndex in pre-test significantly predicted children's pre-test creativity scores. However, teachers' CFTIndex scores in mid-test and post-test did not significantly predict children's mid-test and post-test creativity scores respectively.

As seen from the standardised and unstandardised coefficients of teachers' CFTIndex regressed towards children's creativity in pre-test, there was an adverse effect of teachers' CFB on children's creativity. At pre-test, teachers mainly focused on modifying the mode of assessment and designing activities for children. Teachers did not follow children's learning progress, nor asked questions to support their ideas and guide them to think creatively. Thus, teachers' pedagogical approach indeed had an adverse effect on children's creativity in pre-test. 
From the regression analysis of the effect of teachers' CFTIndex on children's creativity, it was found that the unstandardised and standardised coefficients in pre-test had decreased from $b=-4.759, \beta=-.277$ to $b=-.181, \beta=-.013$ in mid-test and $b=-.839, \beta=-.039$ in post-test. From this result, it was shown that the adverse effect of teachers' CFB was reduced in mid-test and post-test compared to those of pre-test, which meant that teachers' CFB in mid-test and post-test did not cause children to become less creative. During the second phase in the reform process, the child-centred curriculum had become stable progressively. Teachers' pedagogical approach had gradually become less teacher-directed and more child-centred. Open-ended questions were used to explore children's interests and experiences, so as to set up the contents of the thematic sessions and the open classroom activities in accordance with their learning progress, interests, experiences and capabilities. In addition, classrooms were opened up and open-ended materials were adopted to provide opportunities for children to think more deeply and creatively.

\subsection{The Re-Positioning of Assessment in Curriculum Reform}

Formative assessment has been considered as important in the early childhood educational settings in existing research (Aras, 2019; Dunphy, 2010; Pellegrini, 2001). Teachers could promptly diagnose children's learning difficulties and make corresponding teaching and learning modifications to enhance children's learning (Berry, 2008; Brown, 2005; Wiliam, 2011). However, many teachers and educators are unconscious that both the timing and proper positioning of formative assessment have important roles to play in leading a lasting and complete implementation of curriculum reform that would foster children's and teachers' abilities. The current study enlightened educators to take advantage of the nature of formative assessment and to reconsider the proper positioning of formative assessment in a curriculum reform process. By adopting a "flipped-measure" or re-positioning formative assessment in curriculum reform, it means that formative assessment should be assigned a pivotal status or should be placed at the centre of the curriculum reform process, i.e. fulfilling the contents and purpose of formative assessment. Fullan's theory of educational change (2001) emphasised the importance of transformation of multiple components to reach a lasting and complete implementation of curriculum change. This underlined that transformation requires prudent consideration, e.g. simply modifying the contents of the curriculum without providing any concrete directions for teachers is susceptible to hit-and-miss, yet adopting a new mode of assessment without considering its nature and mechanisms involved are also undesirable.

In the current study, teachers tried to collect information to include in the Learning Portfolio. However, the first phase of the curriculum modifications was too modest which caused teachers to find difficulties in fulfilling the contents in the Learning Portfolio. Teachers could not get children to express ideas relating to the topics, and hence, could not obtain much information to support the de- 
velopment of the four core abilities involved in the Learning Portfolio. In order to fulfill the contents in the Learning Portfolio, the curriculum and pedagogy had to be changed in a way that matched with the contents of the Learning Portfolio, which involved in opening up the classroom, using open-ended materials and adopting scaffolding techniques to scaffold children's ideas.

Besides, results showed that there was a slightly larger increase in children's creativity and teachers' $\mathrm{CFB}$ in the second phase compared to those in the first phase of the newly-adopted curriculum. This is because the mode of assessment, the curriculum and the pedagogical mode in the second phase was aligned. The new mode of assessment induced a positive backwash effect of the assessment on the curriculum and pedagogy. In fact it was leading the second phase of the newly-adopted curriculum into a child-centred curriculum and pedagogical mode. It was also the key to the desired results in children's creativity performance and teachers' CFB in the current study. This suggested that assessment should be given a pivotal role in the curriculum reform process and should be a crucial and indispensable part of the changes in a reform process. When conducting a reform geared towards a child-centred curriculum, educators should always consider what impact the mode of assessment would bring to the curriculum and the whole reform process, and modify the mode of assessment, i.e. replacing worksheets, tests and examinations with learning portfolios, so that the mode of assessment would not lead to a negative backwash effect on the new curriculum.

\subsection{Limitations and Future Studies}

In the current study, modifications in the mode of assessment and curriculum were carried out within the whole school. It was impossible to carry out modifications in only a few particular classes in real-world situation. It would be challenging to convince parents why particular classes were chosen to participate in the reform while others not. Hence, the school would either choose to conduct modifications in the mode of assessment and curriculum within the whole school or not to conduct any changes. This has caused the current study to have no control group to determine if any changes in the outcome scores would have been occurred even without the application of the newly-adopted child-centred curriculum and formative assessment, i.e. it was possible that mere maturation might cause a change in outcome scores. In order to address this limitation, regression analysis was used to examine the effect of maturation on children's creativity scores. Results showed that the effect of maturation did not contribute largely to children's mid-test and post-test creativity. In future studies, another kindergarten with a teacher-directed curriculum and a summative assessment scheme could be included into the study, so as to compare different approaches and to explore whether the effect of the child-centred curriculum and formative assessment predominantly leads to improvements in children's creativity.

Another limitation is that the effect of other potentially confounding variables on children's creativity were not controlled for, including teachers' teaching ex- 
perience, and teachers' perspectives towards the newly-adopted child-centred curriculum and this study. Previous research suggested that teachers with more teaching experience showed greater support in students' learning which would enhance students' achievement (Kini \& Podolsky, 2016). Moreover, it was uncertain if every teacher participant was consistent with the orientations of the kindergarten and accepted the implementation of the newly-adopted curriculum and formative assessment. Previous research demonstrated that it was possible that there might still be many old conceptions lied behind the new perspectives adopted by the teachers (Ponte et al., 1994). And due to Hawthorne effect, teachers might rate themselves higher on the CFTIndex questionnaire or even perform better when they knew that they were being observed in this study (Wickström \& Bendix, 2000). Without having a direct conversation with the teachers, whether teachers would be fond of conducting the modifications in assessment and curriculum was unclear. In addition, it was unclear if teachers' self-reported CFTIndex questionnaire and classroom observations would reflect their perspectives and attitudes towards the newly-adopted child-centred curriculum and formative assessment. As teachers' teaching experience and their perspectives and attitudes on curriculum and assessment were not controlled for in the current study, it was unclear if these confounding variables would play a significant role in mediating the effect of teachers' CFB on children's creativity. Future studies could consider conducting interviews with teachers to have an in-depth understanding of their perspectives and attitudes towards the changes in assessment and curriculum.

\section{Conflicts of Interest}

The authors declare no conflicts of interest regarding the publication of this paper.

\section{References}

Alderson, J. C., \& Wall, D. (1993). Does Washback Exist? Applied Linguistics, 14, 115-129. https://doi.org/10.1093/applin/14.2.115

Aras, S. (2019). Improving Early Childhood Teachers' Formative Assessment Practices: Transformative Role of Collaborative Action Research. Uluslararası Eğitim Programları ve Öğretim Çalışmaları Dergisi, 9, 221-240. https://doi.org/10.31704/ijocis.2019.010

Berry, R. (2008). Assessment for Learning (Vol. 1). Hong Kong: Hong Kong University Press.

Berry, R. (2011). Assessment Trends in Hong Kong: Seeking to Establish Formative Assessment in an Examination Culture. Assessment in Education: Principles, Policy \& Practice, 18, 199-211. https://doi.org/10.1080/0969594X.2010.527701

Brown, S. (2005). Assessment for Learning. Learning and Teaching in Higher Education, 1, 81-89.

Chan, S., \& Yuen, M. (2014). Personal and Environmental Factors Affecting Teachers' Creativity-Fostering Practices in Hong Kong. Thinking Skills and Creativity, 12, 69-77. https://doi.org/10.1016/j.tsc.2014.02.003

Cheng, L. (1997). How Does Washback Influence Teaching? Implications for Hong Kong. 
Language and Education, 11, 38-54. https://doi.org/10.1080/09500789708666717

Cropley, A. J. (1997). Fostering Creativity in the Classroom: General Principles. In M. Runco (Ed.), The Creativity Research Handbook (Vol. 1, pp. 83-114). Cresskill, NJ: Hampton Press.

Curtis, A., \& Cheng, L. (2004). Washback or Backwash: A Review of the Impact of Testing on Teaching and Learning. In Washback in Language Testing (pp. 25-40). London: Routledge. https://doi.org/10.4324/9781410609731-9

Dunphy, E. (2010). Assessing Early Learning through Formative Assessment: Key Issues and Considerations. Irish Educational Studies, 29, 41-56. https://doi.org/10.1080/03323310903522685

Fullan, M. (2001). The New Meaning of Educational Change. London: Routledge. https://doi.org/10.4324/9780203986561

Harris, A., Day, C., Hopkins, D., Hadfield, M., Hargreaves, A., \& Chapman, C. (2013). Effective Leadership for School Improvement. London: Routledge. https://doi.org/10.4324/9780203754849

Kini, T., \& Podolsky, A. (2016). Does Teaching Experience Increase Teacher Effectiveness. A Review of the Research (pp. 1-72). Palo Alto, CA: Learning Policy Institute.

Kirkpatrick, R., \& Zang, Y. (2011). The Negative Influences of Exam-Oriented Education on Chinese High School Students: Backwash from Classroom to Child. Language Testing in Asia, 1, 36. https://doi.org/10.1186/2229-0443-1-3-36

Li, Z., \& Li, L. (2019). An Examination of Kindergarten Teachers' Beliefs about Creative Pedagogy and Their Perceived Implementation in Teaching Practices. Thinking Skills and Creativity, 32, 17-29. https://doi.org/10.1186/2229-0443-1-3-36

Lo, Y. C. J. (2005). Curriculum Reform. In Education and Society in Hong Kong and Macao (pp. 161-174). Dordrecht: Springer.

Macao Special Administrative Region (2014). Formal Curriculum Framework for Local Schools [Administrative Regulation No. 15/2014, 25th June 2014]. Macao: The Author. https://images.io.gov.mo/bo/i/2014/26/rega-15-2014.pdf

Macao Special Administrative Region (2015). Requirements of Basic Academic Competencies in Early Childhood Education [Dispatch of the Secretary for Social and Cultural Affairs No. 118/2015, 27th July 2015]. Macao: The Author.

https://images.io.gov.mo/bo/i/2015/30/despsasc-118-2015.pdf

Pellegrini, A. D. (2001). The Role of Direct Observation in the Assessment of Young Children. The Journal of Child Psychology and Psychiatry and Allied Disciplines, 42, 861-869. https://doi.org/10.1017/S002196300100765X

Ponte, J. P., Matos, J. F., Guimarães, H. M., Leal, L. C., \& Canavarro, A. P. (1994). Teachers' and Students' Views and Attitudes towards a New Mathematics Curriculum: A Case Study. Educational Studies in Mathematics, 26, 347-365. https://doi.org/10.1017/S002196300100765X

Posner, G. J. (1994). The Role of Student Assessment in Curriculum Reform. Peabody Journal of Education, 69, 91-99. https://doi.org/10.1080/01619569409538788

Pyle, A., \& DeLuca, C. (2017). Assessment in Play-Based Kindergarten Classrooms: An Empirical Study of Teacher Perspectives and Practices. The Journal of Educational Research, 110, 457-466. https://doi.org/10.1080/01619569409538788

Robinson, K. (2013). How to Escape Education's Death Valley [Video File]. https://www.ted.com/talks/sir ken robinson how to escape education s death valle y

Seng, T. O. (2000). Thinking Skills, Creativity, and Problem-Based Learning. Temasek 
Polytechnic Singapore.

Soh, K. (2015). Creativity Fostering Teacher Behaviour around the World: Annotations of Studies Using the CFT Index. Cogent Education, 2, Article ID: 1034494. https://doi.org/10.1080/2331186X.2015.1034494

Soh, K. C. (2000). Indexing Creativity Fostering Teacher Behavior: A Preliminary Validation Study. The Journal of Creative Behavior, 34, 118-134. https://doi.org/10.1002/j.2162-6057.2000.tb01205.x

Vong, K. I. P., \& Vong, S. K. (2017). Early Childhood Education in Macao: Recent Policies, Developments, and Trends. In Early Childhood Education in Chinese Societies (pp. 171-183). Berlin: Springer. https://doi.org/10.1007/978-94-024-1004-4 11

Vong, K. I. P., Cheng, D. P. W., Wu, H. P., Kam, C. C. S., \& Liu, K. (2017). Effects of High-Activity and High-Energy Play vs. Low-Activity and Low-Energy Play on Hong Kong Preschool Boys' and Girls' Creativity. Creative Education, 8, 2377. https://doi.org/10.4236/ce.2017.815162

Wickström, G., \& Bendix, T. (2000). The "Hawthorne Effect"-What Did the Original Hawthorne Studies Actually Show? Scandinavian Journal of Work, Environment \& Health, 26, 363-367. https://doi.org/10.5271/sjweh.555

Wiliam, D. (2011). What Is Assessment for Learning? Studies in Educational Evaluation, 37, 3-14. https://doi.org/10.1016/j.stueduc.2011.03.001

Wong, N. C. M., \& Rao, N. (2004). Preschool Education. In Education and Society in Hong Kong and Macau: Comparative Perspectives on Continuity and Change (2nd Ed., pp. 15-34). Dordrecht: Springer.

Wu, J. (2016). Educational Discipline, Ritual Governing, and Chinese Exemplary Society: Why China's Curriculum Reform Remains a Difficult Task. Policy Futures in Education, 14, 721-740. https://doi.org/10.1177/1478210316645248

Yan, C. (2015). "We Can't Change Much unless the Exams Change": Teachers' Dilemmas in the Curriculum Reform in China. Improving Schools, 18, 5-19. https://doi.org/10.1177/1365480214553744

Yeh, Y. C., Li, M. L., Yeh, Y. H., Lin, C. C., \& Peng, Y. Y. (2006). The Development of “The Preschoolers" Creativity Test. Psychological Testing, 53, 129-153. (In Chinese)

Yu, W. M., Kennedy, K. J., Fok, P. K., \& Chan, J. K. S. (2006). Assessment Reform in Basic Education in Hong Kong: The Emergence of Assessment for Learning. Educational Assessment, 21, 26.

Zhao, Y. (2018). Shifting the Education Paradigm: Why International Borrowing Is No Longer Sufficient for Improving Education in China. ECNU Review of Education, 1, 76-106. https://doi.org/10.1177/1365480214553744 
Appendix A. Characteristics of the "old" and "newly-adopted" curriculum.

\begin{tabular}{|c|c|c|c|}
\hline & \multirow{2}{*}{$\begin{array}{l}\text { "Old curriculum" before the } \\
\text { current study }\end{array}$} & \multicolumn{2}{|c|}{ 'Newly-adopted curriculum' in the current study } \\
\hline & & First phase & Second phase \\
\hline Duration & $\begin{array}{l}\text { Scholastic year } \\
\text { 2015/2016-2016/2017 }\end{array}$ & 09/2017-01/2018 & $01 / 2018-06 / 2018$ \\
\hline Assessment & $\begin{array}{l}\text { - Learning corners record sheets } \\
\text { - Tests and examinations }\end{array}$ & - Child Development and Learning Portfolio & - Child Development and Learning Portfolio \\
\hline $\begin{array}{l}\text { Flow of } \\
\text { classroom } \\
\text { activities }\end{array}$ & $\begin{array}{l}\text { Whole-group thematic session } \\
\text { (teachers discussed a theme with } \\
\text { children) } \\
\downarrow \\
\text { Small-group activities in learning } \\
\text { corners } \\
\text { (children completed pre-assigned } \\
\text { tasks) } \\
\downarrow \\
\text { Whole-group sharing session } \\
\text { (children shared what they did in } \\
\text { the learning corners) }\end{array}$ & $\begin{array}{l}\text { Whole-group thematic session } \\
\text { (teachers discussed a theme with children) } \\
\downarrow \\
\text { Small-group activities in learning corners } \\
\text { (children discussed with their teachers what } \\
\text { activities they wanted to engage in, what } \\
\text { materials to use to complete their tasks, and } \\
\text { with whom they wanted to collaborate with) } \\
\downarrow \\
\text { Whole-group sharing session } \\
\text { (children shared what they did in the } \\
\text { learning corners) }\end{array}$ & $\begin{array}{l}\text { Whole-group thematic session } \\
\text { (teachers discussed a theme with children; used } \\
\text { open-ended questions to explore children's } \\
\text { interests, experiences, and capabilities) } \\
\downarrow \\
\text { Small-group open classroom activities } \\
\text { (children discussed with their teachers what } \\
\text { activities they wanted to engage in, what } \\
\text { materials to use to complete their tasks, and with } \\
\text { whom they wanted to collaborate with; amount } \\
\text { of time for activities depended on children's } \\
\text { progress) } \\
\downarrow \\
\text { Whole-group sharing session } \\
\text { (children shared the process, outcome, obstacles, } \\
\text { and improvement plans of their open classroom } \\
\text { activities) }\end{array}$ \\
\hline Pedagogy & $\begin{array}{l}\text { - Teacher-directed (students follow } \\
\text { teachers' instructions) } \\
\text { - Teachers taught lessons according } \\
\text { to teaching kit. } \\
\text { - Lack of consideration of children's } \\
\text { interests, experiences and } \\
\text { capabilities }\end{array}$ & $\begin{array}{l}\text { - Teacher-directed (students follow teachers' } \\
\text { instructions) } \\
\text { - Teachers taught lessons according to lesson } \\
\text { plans. } \\
\bullet \text { Lack of consideration of children's } \\
\text { interests, experiences and capabilities }\end{array}$ & $\begin{array}{l}\text { - Child-centred (teachers acted as a role of } \\
\text { guidance and scaffolded children's ideas; } \\
\text { children engaged in activities they were } \\
\text { interested in; opportunities for children to learn } \\
\text { autonomously and explore the themes actively) } \\
\text { - Teachers developed open classroom activities } \\
\text { based on children's interests, experiences and } \\
\text { capabilities } \\
\text { - No preset goals and teaching contents }\end{array}$ \\
\hline $\begin{array}{l}\text { Learning } \\
\text { environment }\end{array}$ & $\begin{array}{l}\text { - Multiple learning corners (arts, } \\
\text { science, literacy, manipulatives } \\
\text { and puzzles) }\end{array}$ & $\begin{array}{l}\text { Multiple learning corners (arts, science, } \\
\text { literacy, manipulatives and puzzles) }\end{array}$ & $\begin{array}{l}\text { - Open classroom with large and flexible open } \\
\text { spaces provided opportunities for active } \\
\text { learning and individualised instruction }\end{array}$ \\
\hline $\begin{array}{l}\text { Teaching } \\
\text { materials }\end{array}$ & - Pre-designed teaching aids & - Pre-designed teaching aids & $\begin{array}{l}\text { - Open-ended materials (natural materials, e.g. } \\
\text { stones, sand, leaves; manufactured materials, } \\
\text { e.g. boxes, bottles, cardboard) }\end{array}$ \\
\hline
\end{tabular}

